\title{
Correlation Between The Severity And Outcome Of Acute Calculous Cholecystits According To Tokyo Guidelines
}

\author{
Thapa $\mathrm{P}^{1}$, Adhikari KM ${ }^{2}$ Sharma $\mathrm{A}^{3}$
}

\begin{abstract}
Introduction: Acute Calculous Cholecystitis is a condition in which the gallbladder becomes inflamed due to cholelithiasis. Early diagnosis, severity grading and appropriate intervention reduce both morbidity and mortality. The aim of this prospective study is to correlate the severity with the outcome of acute calculous cholecystitis according to Tokyo Guidelines. Methods: This was a hospital based prospective study conducted in the Department of Surgery, Nepalgunj Medical College Teaching Hospital for a period of two years from April 2017 to March 2019. The patients were classified into three groups according to the severity grading in the Tokyo guidelines (TG18/TG13). Clinical characteristics among these patients were analyzed for comparison.

Results: Among all diagnostic criteria, right upper quarter (RUQ)h abdominal pain (94\%) Murphy's sign (94\%) and thickened gallbladder wall $(80 \%)$ had the highest sensitivity rates $(p<0.032)$, whereas elevated white cell count $(32 \%)$ and RUQ abdominal mass $(32 \%)$ had the lowest sensitivity rates $(p<0.035)$. Higher sensitivity rates of diagnostic criteria were related to severe cholecystitis, except for Fever (46\%) and elevated white blood cell (WBC) count (32\%). All the 28 patients in grade I and selected patients 3 out of 6 in grade II underwent early laparoscopic cholecystectomy (LC) without any conversion and increased morbidity and mortality. Out of 16 patients in grade III there was 2 mortalities due to ARDS, 1 needed Ultrasonography (USG) guided cholecystostomy, 1 underwent emergency cholecystectomy. 16 patients, 3 in grade II and 13 in grade III underwent interval laparoscopic cholecystectomy safely. There were no major postoperative morbidities except for superficial surgical site infection (SSI) in 1 patient in grade III who underwent emergency cholecystectomy Higher grade of severity was associated with increased morbidity and mortality $(p<0.03)$. Conclusion: A combination of diagnostic criteria with different pathophysiologic findings, as noted in the Tokyo guidelines, can help clinicians make the correct diagnosis for patients with acute cholecystitis and there was strong correlation between the severity and outcomes of acute cholecystitis.
\end{abstract}

Key words: Cholecystitis, cholecystectomy, Murphy's sign, Tokyo guidelines, Ultrasound

\section{INTRODUCTION}

Cholecystitis is inflammation of the gallbladder. cholecystitis occurs most commonly due to blockage of the cystic duct with gallstones (cholelithiasis) ${ }^{1,2}$. Concentrated bile, pressure, and sometimes bacterial infection irritate and damage the gallbladder wall, causing inflammation and swelling of the gallbladder ${ }^{1}$. Acute Cholecystitis (AC) is diagnosed based on the characteristic symptoms of right upper abdominal pain, nausea, vomiting and fever as well as laboratory testing

1. Dr. Pradip Thapa

2. Dr. Krishna Mohan Adhikari

3. Dr. Anup Sharma

\section{Address for Correspondence:}

Dr. Pradip Thapa

Lecturer

Department of Surgery

Nepalgunj Medical College \& Teaching Hospital

Kohalpur, Banke, Nepal showing an increased white blood count ${ }^{3}$. Abdominal ultrasound is widely used in diagnosis ${ }^{4}$. As is well known, early diagnosis of acute cholecystitis allow prompt treatment and reduces both mortality and morbidity. Therefore, the Tokyo Guidelines (TG-07) were proposed for the diagnosis and severity assessment of acute cholecystitis, based on the best available evidence and the expert's consensus ${ }^{4}$ which was modified to Tokyo Guidelines (TG 13) and then in 2018, adopted unchanged as Tokyo Guidelines TG18/ TG13 in light of results from many validation studies ${ }^{5}$.

Acute cholecystitis (AC) is very common problem in Nepal. But there is paucity of report regarding the use of TG 18/ TG13 for diagnosis and to assess the severity of AC in Nepal. Therefore, this study was conducted for the diagnosis and evaluation of a severity grading of acute cholecystitis in this part of Nepal.

\section{MATERIAL AND METHODS}

This was a hospital based prospective study conducted in the Department of Surgery, Nepalgunj Medical College Teaching Hospital from April 2017 to March 2019. All patients with suspected diagnosis of Acute calculous cholecystitis were included. Patients with acute acalculous cholecystitis; acute 
cholecystitis associated with malignancy of gallbladder, bile duct, liver or pancreas; Diabetic patient; immunocompromised patient; already treated patients; ascites were excluded.

Clinical diagnosis of acute cholecystitis was made by the presence of one of the local signs of inflammation Murphy's sign, RUQ abdominal pain or mass or tenderness assessed by physical examination and one of the systemic signs of inflammation i.e. fever, elevated WBC count and elevated CRP ${ }^{8}$. Ultrasonography of abdomen and pelvis wad done in all cases to confirm the diagnosis and if it showed one of the following findings the diagnosis was confirmed.1. Enlarged gall bladder 2.Thickening of gall bladder wall 3. Gall bladder stones 4 . Pericholecystic fluid5. Positive Sonographic Murphy's sign ${ }^{15}$.

These patients were classified in to 3 grades of severity as: A) Mild (Grade I): 1. No organ dysfunction 2. Disease limited to GB. B) Moderate (Grade II): 1. No organ dysfunction 2. Extended Disease of GB 3. WBC increased 4. Palpable / tender mass 5. Duration $>72$ hours 6 . Significant inflammatory change in Gall bladder on USG)

Severe (Grade III): Presence of dysfunction of any one of the following organs/systems:

1. Cardiovascular dysfunction Hypotension requiring treatment with dopamine $>5 \mathrm{ug} / \mathrm{kg}$ per min, or any dose of norepinephrine

2. Neurological dysfunction Decreased level of consciousness

3. Respiratory dysfunction $\mathrm{PaO} 2 / \mathrm{FiO} 2<300$

4. Renal dysfunction Oliguria, creatinine $[>2.0 \mathrm{mg} / \mathrm{dl}]$

5. Hepatic dysfunction PT-INR [>1.5]

6. Hematological dysfunction Platelet count $<100,000 / \mathrm{mm} 3$

The patients were managed according to the management protocol of Tokyo's guidelines depending up on the grade. All patients with grade I and grade II severity who presented within 72 hours and those who didn't have palpable gall bladder underwent cholecystectomy within same hospital admission. Those patients who presented after 72 hours and had palpable mass were treated conservatively and were operated electively after six weeks. Patients with grade III severity were managed conservatively in Intensive Care Unit (ICU). USG guided cholecystostomy or emergency cholecystectomy was performed in case of deterioration of signs and symptoms or rising WBC count and worsening biochemical parameters like renal function, liver function tests.

This was the end point for assessment of severity and its out comes in patient with acute cholecystitis according to Tokyo's guidelines.

All data were analyzed using statistical Package for Social Science (SPSS).

\section{RESULTS}

Over a period of 2 years, 50 patients met the criteria for inclusion. There were 39 (78\%) females and $11(22 \%)$ males. The mean age of patient was $46.44 \pm 16.59$ years. According to the severity grading mean age of patient was $40.14 \pm 15.53$, $45.83 \pm 14.40$ and $57.69 \pm 13.69$ years respectively in grade I, II and III respectively. According to the severity grading of Tokyo's guidelines (TG18/TG13) 28(56\%) cases were graded as grade I, $6(12 \%)$ cases as grade II and $16(32 \%)$ cases as grade III. Out of 50, 47 (94\%) cases had positive Murphy's sign. Right upper quadrant (RUQ) pain was seen in $47(94 \%)$ whereas RUQ mass was observed in $16(32 \%)$ cases. (Table I)

\begin{tabular}{|c|c|c|c|c|}
\hline \multirow{2}{*}{$\begin{array}{l}\text { Local sign of } \\
\text { inflammation }\end{array}$} & \multicolumn{3}{|l|}{ Grade } & \multirow{2}{*}{$\begin{array}{l}\text { Total } \\
\text { (50) }\end{array}$} \\
\hline & I(28) & ॥(6) & $\mathrm{III}(16)$ & \\
\hline Murphy's sign & $25(50 \%)$ & $6(12 \%)$ & $16(32 \%)$ & $47(94 \%)$ \\
\hline RUQ pain & $25(50 \%)$ & $6(12 \%)$ & $16(32 \%)$ & $47(94 \%)$ \\
\hline RUQ mass & $2(4 \%)$ & $5(10 \%)$ & $9(18 \%)$ & $16(32 \%)$ \\
\hline
\end{tabular}

Table I: Distribution of local signs of inflammation and Grading of Severity

Out of 28 cases of grade I, 25 (89\%) were having murphy's sign positive. All $6(100 \%)$ cases of grade II and all $16(100 \%)$ cases of grade III were having murphy's sign positive. Presence of Murphy's sign was significant and indicated higher grade of severity of disease $(p<0.032)$.

In severity of grading system 25 (89\%) cases of grade I, $6(100 \%)$ cases of grade II, and $16(100 \%)$ cases of grade III were having $R \cup Q$ pain. RUQ pain was a significant finding in the assessment of severity $(p<0.034)$.

\begin{tabular}{|l|l|l|l|}
\hline $\begin{array}{l}\text { Systemic sign of } \\
\text { Inflammation }\end{array}$ & $\begin{array}{l}\text { Grade } \\
\text { I }\end{array}$ & $\begin{array}{l}\text { Grade } \\
\text { II }\end{array}$ & $\begin{array}{l}\text { Grade } \\
\text { III }\end{array}$ \\
\hline Fever & $5(10 \%)$ & $6(12 \%)$ & $12(24 \%)$ \\
\hline Elevated WBC count & 0 & $6(12 \%)$ & $10(20 \%)$ \\
\hline Elevated CRP & $4(8 \%)$ & $6(12 \%)$ & $16(32 \%)$ \\
\hline
\end{tabular}

Table II: Comparison of Systemic signs of inflammation with grades of $\mathrm{AC}$

In grade I out of 28 cases, $5(10 \%)$ cases were having fever, in grade II all 6 cases (100\%) were having fever and in grade III out of 16 cases, 12 (75\%) cases were having fever.

Out of 50 patients, 16 (32\%) had elevated WBC count. None of the patients in grade I had elevated WBC Count, all $6(100 \%)$ patients in severity grade II and $10(62.5 \%)$ in severity grade III had elevated WBC count. Elevated WBC count was associated with increase in severity of disease with $p$ value of 0.035 $(\mathrm{p}<0.035)$. (Table II) 


\begin{tabular}{|l|l|l|l|l|}
\hline $\begin{array}{l}\text { Sonographic } \\
\text { finding }\end{array}$ & $\begin{array}{l}\text { Grade I } \\
28(56 \%)\end{array}$ & $\begin{array}{l}\text { Grade } \\
\text { II } \\
6(12 \%)\end{array}$ & $\begin{array}{l}\text { Grade III } \\
16(32 \%)\end{array}$ & $\begin{array}{l}\text { Total } \\
50(100 \%)\end{array}$ \\
\hline $\begin{array}{l}\text { GB wall } \\
\text { thickness>4 } \\
\text { mm }\end{array}$ & $18(36 \%)$ & $6(12 \%)$ & $16(32 \%)$ & $40(80 \%)$ \\
\hline $\begin{array}{l}\text { Pericholecystic } \\
\text { collection }\end{array}$ & $5(10 \%)$ & $4(8 \%)$ & $14(28 \%)$ & $23(46 \%)$ \\
\hline Enlarged GB & $9(18 \%)$ & $4(8 \%)$ & $15(30 \%)$ & $28(56 \%)$ \\
\hline $\begin{array}{l}\text { POSISTIVE } \\
\text { SONOGRAPHIC } \\
\text { MURPHY'S } \\
\text { SIGN }\end{array}$ & $8(16 \%)$ & $4(8 \%)$ & $16(32 \%)$ & $28(56 \%)$ \\
\hline
\end{tabular}

Table III: Comparison of USG findings with Grades of AC

40 patients had GB wall thickened ( $>4 \mathrm{~mm}$ ) on USG. Among them $18(36 \%)$ were in grade I, $6(12 \%)$ in grade II and $16(32 \%)$ in grade III. Out of $23(46 \%)$ patients having songraphic finding of pericholecystic collection, there were $5(10 \%)$ patients with grade I, $4(8 \%)$ with grade II and $14(28 \%)$ with grade III. Out of $28(56 \%)$ patients with enlarged gall bladder, there were $9(18 \%)$ patients in severity grade I, $4(10 \%)$ in severity grade II and $15(30 \%)$ in severity grade III. Enlarged gall bladder was least common sonographic finding to confirm AC. 28(56\%) had positive sonological Murphy's sign. Among them $8(16 \%)$ were in grade I, $4(8 \%)$ in grade II and $16(32 \%)$ in grade III. (Table 3 )

There were 16 patients in grade III. Out of 16 patients, 10(62\%) had hypotension only, 3(19\%) had hypotension as well as Acute Kidney Injury (AKD) and 3(19\%) patients had Acute Respiratory Distress Syndrome (ARDS) and AKI. All patients were managed in ICU. None of the patients with AKD required Hemodialysis (HD). 6 patients needed ionotrope support for hypotension refractory to fluid resuscitation. Among 3 patients with ARDS and AKI who were on Mechanical Ventilation (MV), there were 2 (4\%) mortalities due to ARDS and 1patient needed USG guided cholecystostomy due to empyema gall bladder not improving with antibiotics, patient improved, was out of ventilator and discharged. 1 (2\%) patient with hypotension and AKI developed generalized peritonitis during ICU admission, bedside USG was done which showed collection in Morrison's space revealing bile on aspiration, and thus emergency open cholecystectomy was done. Intraoperatively he had gangrenous cholecystitis with perforation, patient did well.

All 28 patients in grade I and 3 patients in grade II who presented within 72 hours and didn't have palpable GB underwent early laparoscopic cholecystectomy (LC) on same hospital admission. There was no conversion in grade I, 1 patient in grade II who underwent early cholecystectomy had to be converted due to dense adhesions. No mortality in grade I and II, 2 mortality in grade III. 3 patients in grade II and 13 patients in grade III underwent elective LC after 6-8 weeks, and there was no conversion to open cholecystectomy. Patient undergoing emergency cholecystectomy had superficial surgical site infection (SSI) which healed with dressing and antibiotic therapy. As the grade of severity of AC increased the morbidities and mortalities increased $(p<0.03$ ) (Table IV)

\begin{tabular}{|l|l|l|l|l|l|l|l|l|l|}
\hline Grade & $\begin{array}{l}\text { Early } \\
\text { LC }\end{array}$ & $\begin{array}{l}\text { Emer } \\
\text { gency } \\
\text { chole } \\
\text { cystec } \\
\text { tomy }\end{array}$ & $\begin{array}{l}\text { Interval } \\
\text { LC }\end{array}$ & $\begin{array}{l}\text { Postop } \\
\text { complica } \\
\text { tion }\end{array}$ & $\begin{array}{l}\text { Cholecys } \\
\text { tostomy }\end{array}$ & $\begin{array}{l}\text { lonotrope } \\
\text { support }\end{array}$ & HD & MV & Mortality \\
\hline I(28) & $\begin{array}{l}28 \\
(56 \%)\end{array}$ & 0 & 0 & 0 & 0 & 0 & 0 & 0 & 0 \\
\hline II(6) & $\begin{array}{l}3 \\
(6 \%)\end{array}$ & 0 & $3(6 \%)$ & 0 & 0 & 0 & 0 & 0 & 0 \\
\hline III(16) & 0 & $1(2 \%)$ & $13(26 \%)$ & $1(2 \%)$ & $1(2 \%)$ & $6(12 \%)$ & 0 & $\begin{array}{l}3 \\
(6 \%)\end{array}$ & $2(4 \%)$ \\
\hline $\begin{array}{l}\text { Total } \\
(50)\end{array}$ & $\begin{array}{l}31 \\
(62 \%)\end{array}$ & $1(2 \%)$ & $16(32 \%)$ & $1(2 \%)$ & $1(2 \%)$ & $612 \%)$ & 0 & $\begin{array}{l}3 \\
(6 \%)\end{array}$ & $2(4 \%)$ \\
\hline
\end{tabular}

Table IV: Correlation of Severity of AC with Outcomes

\section{DISCUSSION}

In present study Murphy's sign (94\%) and tenderness (94\%) in the RUQ abdomen are frequent signs, followed by fever (58\%), a palpable abdominal mass (32\%), systemic sepsis and organ failure $(20 \%)^{6,7}$. The gold standard for diagnosis of acute cholecystitis is pathological examination of the gallbladder. There is still controversy regarding the optimal criteria for clinical diagnosis. Therefore, the Tokyo guidelines were proposed for the diagnosis and severity assessment of acute cholecystitis, based on the best available evidence and the experts' consensus achieved at the International Consensus Meeting for the Management of Acute Cholecystitis and Cholangitis held on 1-2 April 2006 in Tokyo ${ }^{4,8}$. Furthermore, the Tokyo guidelines also provide recommendations for management depending on the severity of acute cholecystitis ${ }^{6}$. Abdominal ultrasonography is the imaging study most commonly used in diagnosis. In studies conducted by Ralls et al. (1985) and Bree et al.(1995), the sensitivity rate for positive ultrasonographic Murphy's sign ranged from 86 to $92 \%$, and the rates for stones and thickening of the gallbladder wall varied from 93 to $95 \%{ }^{9,10}$. Present study also showed a high sensitivity rate for thickened gallbladder wall $(80 \%)$ and a relatively low rate for pericholecystic fluid (46\%) collected as the severity of disease progressed which is similar to study conducted by Lee et al $\mathbf{2 0 1 0}$ which also showed a high sensitivity rate for thickened gallbladder wall (92.3\%) and very low rate for pericholecystic fluid (18.3\%) collected as the severity of disease progressed ${ }^{6}$.

As for local signs of inflammation present study demonstrated that RUQ abdominal pain has sensitivity rate as high as $94 \%$. These values were similar to report of study conducted by 
Ralls et al in $1985^{\circ}$. RUQ abdominal mass, defined as a distended and palpable gall bladder, was less (32\%) in our patients with acute cholecystitis. The incidence was lower; this might be due to the exclusion of malignancy of the bile duct, gallbladder, liver or pancreas in present study.

In present study, $100 \%, 100 \%$ and $90 \%$ of patient of Grade III, II and grade I respectively have Murphy's sign positive, similar to study conducted by Robert et al. in $2003^{11}$. Using a combination of clinical symptoms, signs and laboratory results can help clinicians accurately diagnose acute cholecystitis ${ }^{11}$. Only two studies conducted by Dunlop et al. in 19890 and Gruber et al. in 1996, however, evaluated the diagnostic value of such a combination, and both of them focused on the same underlying pathophysiologic process, such as the combination of fever and leukocytosis, providing no synergistic diagnostic effect ${ }^{12,13}$. Present study demonstrated the diagnostic value of combining findings with independent processes, for example, high sensitivity rates in combination with positive typical image findings, RUQ abdominal pain and elevated C-reactive protein. Comparison of patients with and without typical image findings showed that both RUQ abdominal pain and elevated WBC count had acceptable sensitivity rates for the diagnosis of acute cholecystitis. On the contrary, elevated C-reactive protein had clinical diagnostic value only in those patients who had typical ultrasonography images supporting acute cholecystitis, which was consistent with the results of a study conducted by Juvonen et al. in $1992^{14}$. In this study only $46 \%$ of patient were having fever and $32 \%$ of patient were having elevated WBC count which may be due to patient were already getting antipyretic medication and antibiotic outside.

In study conducted by Kabul et al. (2015), out of 23 patient of Grade III 11 cases (47\%) were observed with renal dysfunction, 8 cases (35\% were observed with hepatic dysfunction, 4 (18\%) cases were observed with cardiac and respiratory dysfunction and none of the patient were observed with neurological dysfunction ${ }^{15}$. In present study out of 16 cases of Grade III, 10 cases (62\%) were observed with hypotension, 3 cases (19\%) were observed with hypotension with AKI, 3 cases (19\%) were observed with ARDS and AKI. None of the patient was observed with neurological dysfunction.

\section{CONCLUSION}

This study demonstrated that RUQ abdominal pain, presence of murphy's sign and thickened gallbladder wall had the highest sensitivity rates among all diagnostic criteria and also indicates higher severity of AC. There was a strong correlation between the severity of the acute cholecystitis and outcomes.

\section{REFERENCES}

1. Steven M. Strasberg, M.D. Acute calculous cholecystitis. N Engl J Med.2008;358:2804-11

2. Longo D.L., Fauci A.S., Kasper D.L .Hauser SL,Jameson L, Anthony $\mathrm{S}$, et al. Diseases of the Gallbladder and Bile Ducts.Harrison's Principle of Internal Medicine. 18ed.McGraw-Hill Companies, Inc:2014;14 (311):2621

3. Papadakis M.A., McPhee S.J., Rabow M.W. Liver, Biliary Tract, \& Pancreas Disorders. Current Medical Diagnosis \& Treatment 2015 ed. McGraw-Hill Education:2014;16:698

4. Hirota M, Takada T, Kawarada Y, Nimura Y, Miura F, Hirata K, et al. Diagnostic criteria and severity assessment of acute cholecystitis: Tokyo guidelines. J Hepatobiliary Pancreat Surg. 2007;14:78-82.

5. Yokoe M, Hata J, Takada T, et al.Tokyo Guidelines 2018; diagnostic criteria and severtiy grading of acute cholecystits. J Hepatobiliary Pancreat Sci 2018; 25:41-54.

6 Adedeji OA, McAdam WA. Murphy's sign, acute cholecystitis and elderly people. J R Coll Surg Edinb. 1996; 41:88-9.

7 Morrow DJ, Thompson J, Wilson SE. Acute cholecystitis in the elderly: a surgical emergency. Arch Surg. 1978; 113:1149-52.

8 Takada T, Kawarada Y, Nimura Y, Yoshida M, Mayumi T, Sekimoto $M$, et al. Background: Tokyo guidelines for the management of acute cholangitis and cholecystitis. J Hepatobiliary Pancreat Surg. 2007;14:1-10.

9 Ralls PW, Colletti PM, Lapin SA, Chandrasoma P, Boswell WD Jr, Ngo C, et al. Real-time sonography in suspected acute cholecystitis: prospective evaluation of primary and secondary signs. Radiology. 1985; 155:767-71.

10 Bree RL. Further observations on the usefulness of the sonographic Murphy sign in the evaluation of suspected acute cholecystitis. J Clin Ultrasound. 1995; 23:169-72.

11 Robert LT, Nicole KR, Kaveh GS. Dose this patient have acute cholecystitis? JAMA. 2003; 289(1):80-6.

12 Dunlop MG, King PM, Gunn AA. Acute abdominal pain. J R Coll Surg Edinb. 1989; 34:124-7.

13 Gruber PJ, Silverman RA, Gottesfeld S, Flaster E. Presence of fever and leukocytosis in acute cholecystitis. Ann Emerg Med. 1996; 28:273-7.

14 Juvonen T, Kiviniemi H, Niemela O, Kairaluoma MI. Diagnostic accuracy of ultrasonography and $\mathrm{C}$ reactive protein concentration in acute cholecystitis: a prospective clinical study. Eur J Surg. 1992;158(6):365-9.

15 Kabul E, Gurbulak B, Akgun IE, Duzkoylu Y, Battal M, Demir $U$ et al. Prediction of the Grade of Acute Cholecystitis by Plasma Level of C-Reactive Protein. Iranian Red Crescent Med J. 2015;17(4):280-91. 